\title{
Heat transfer enhancement in a corrugated tube heat exchanger
}

\section{Djamalutdin Chalaev ${ }^{1}$, Nina Silnyagina ${ }^{1}$, Oleksii Shmatok ${ }^{1}$, Oleksandr Nedbailo ${ }^{1,2}$}

\author{
1 - Institute of Engineering Termophysics of National Academy of Sciences of Ukraine, \\ Kyiv, Ukraine \\ 2 - National University of Food Technologies, Kyiv, Ukraine
}

\begin{tabular}{l} 
Keywords: \\
Heat transfer \\
Exchanger \\
Corrugation \\
Tube \\
Vortex \\
\hline
\end{tabular}

Article history:

Received

12.03.2016

Received in revised form 19.06.2016

Accepted

30.06.2016

\section{Corresponding author:}

Nina Silnyagina

E-mail:

nbs77@rambler.ru

\section{Abstract}

Introduction. The use of corrugated tubes is an effective method of intensification of heat transfer in tubular heat exchangers, but there is currently no universal method of calculation and design of such heat exchangers.

Materials and methods. The heat transfer characteristics of flexible corrugated stainless steel tubes with different corrugation profile were studied. The laboratory stand is a "tube in tube" type heat exchanger with outer smooth tube and inner corrugated tube, equipped with sensors for measuring temperature and hydraulic flow parameters.

Results and discussion. The research of heat transfer and hydrodynamics in the "tube in tube" type heat exchanger with a corrugated inner tube found considerable intensification of heat transfer compared with traditional smooth tube heat exchanger in the range of Reynolds numbers from 4000 to 40000 . The increasing of heat transfer coefficient was from 2.0 to 2.6 times during the increase of the hydraulic resistance in $1,9 \ldots 2,0$ times. It was found that the tubes with the small corrugation height and the big corrugating pitch (height/pitch ratio $-1.9 / 4.0 \mathrm{~mm}$ ) have $15 \ldots$ $20 \%$ higher convective component of the heat transfer coefficient in comparison with tubes with the higher corrugation height and the small corrugation pitch (height/pitch ratio - 2.4/3.2 mm) under identical flow conditions.

Two-dimensional axially symmetric computer model of the unit cell of the heat exchanger was developed to estimate the effect of the tube geometry on the intensity of the heat transfer process. Numerical simulation of hydrodynamics and heat transfer in the unit cell channel showed that mathematical calculations are quite close to the experimental studies.

The heat exchanger with capacity of $350 \mathrm{~kW}$ for the administrative building heating is designed and engineered using criterial dependences. The experimental operation of the heat exchanger confirmed the effectiveness of the proposed technical solutions.

Conclusions. The using of corrugating tubes allowed to increase the heat transfer coefficient. The received criterial dependences allow to calculate and optimize the process of heat transfer in a tubular heat exchanger with flexible corrugated pipes. 


\section{Introduction}

Heat exchangers play an important role in industrial power system. It is a great group of heat-power equipment with considerable industrial areas and often $20 \%$ or more of the total cost of equipment used in thermal power, chemical industry, refining industry, food processing industry, utilities and other industries [1].

Creation of modern heat-exchange equipment is the complicated and multiplane purpose. The expansion of activities focused on the intensification of heat exchange, reducing the weight and dimensions of heat exchangers, increasing their productivity is needed to decrease energy and material consumption as well as saving the cost of heat exchange equipment. The real rationalization of heat exchanger design is considered nearly exhausted today [2].

Heat treatment of liquid products in tubular heat exchangers is often used in the food industry [3]. The high heat transfer performance and low flow resistance losses, compact size and lightness are the main requirement for heat exchangers. The achievement of these requirements is only possible using the intensification of heat exchange.

The intensification of heat exchange is one of the most important directions for development of modern heat-exchange equipment. The intensification of heat exchange is usually of interest providing gain in cost in comparison with standard samples. The method of intensification depends on the availability of materials, safety and reliability. The correlation properties of heat exchangers are presented in Figure 1.

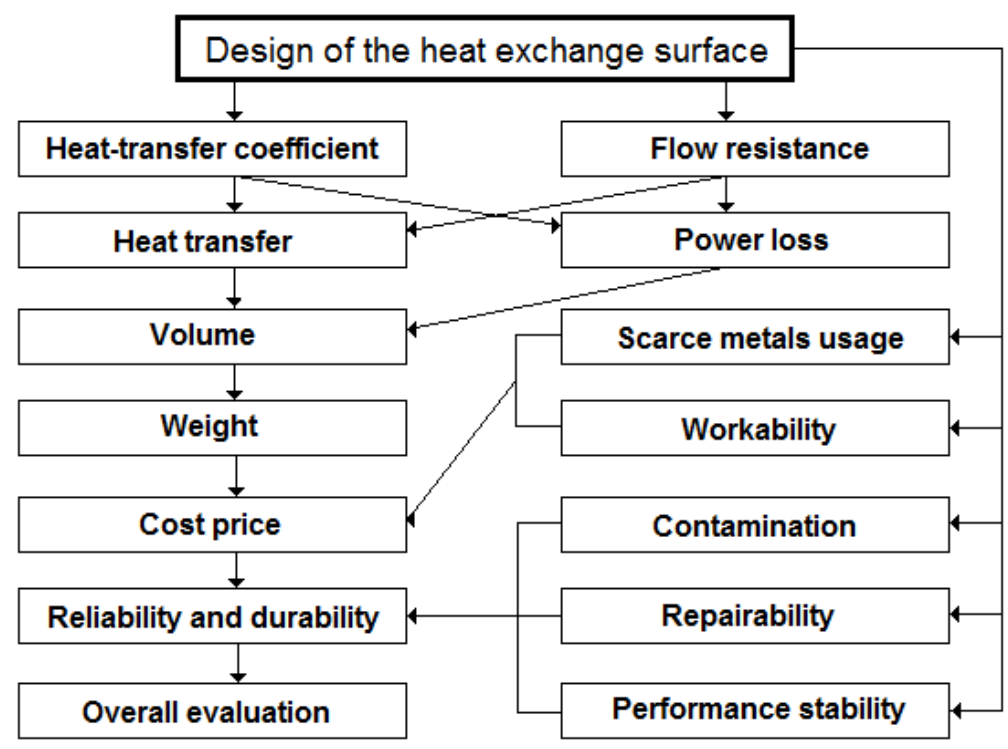

Fig.1. Correlation properties of heat exchangers

The scientific works of foreign and native scientists are constantly studied for search of methods of heat exchange intensification [4-11]. The methods of passive heat exchange intensification and the use of developed heat exchange surfaces are widely applied today. No universal methods and no criteria are developed for efficiency assessment of the heat exchange surfaces. Further in-depth study of the thermal and hydrodynamic processes 
occurring in the developed heat exchange surfaces is required in order to obtain general dependences for calculating the thermal and hydraulic characteristics and to evaluate their efficiency.

The efficiency of the surface itself, its manufacture adaptability, technological efficiency of the heat exchanger, strength requirements, and surface contamination is necessary to consider choosing the method of heat exchange intensification for the practical application.

\section{Materials and methods}

Thin-walled corrugated flexible stainless steel tubes of various modifications are produced by a number of domestic companies today (Figure 2). These tubes are relatively cheap and used extensively for hot and cold water supply systems, heating systems and gas consuming equipment [12].

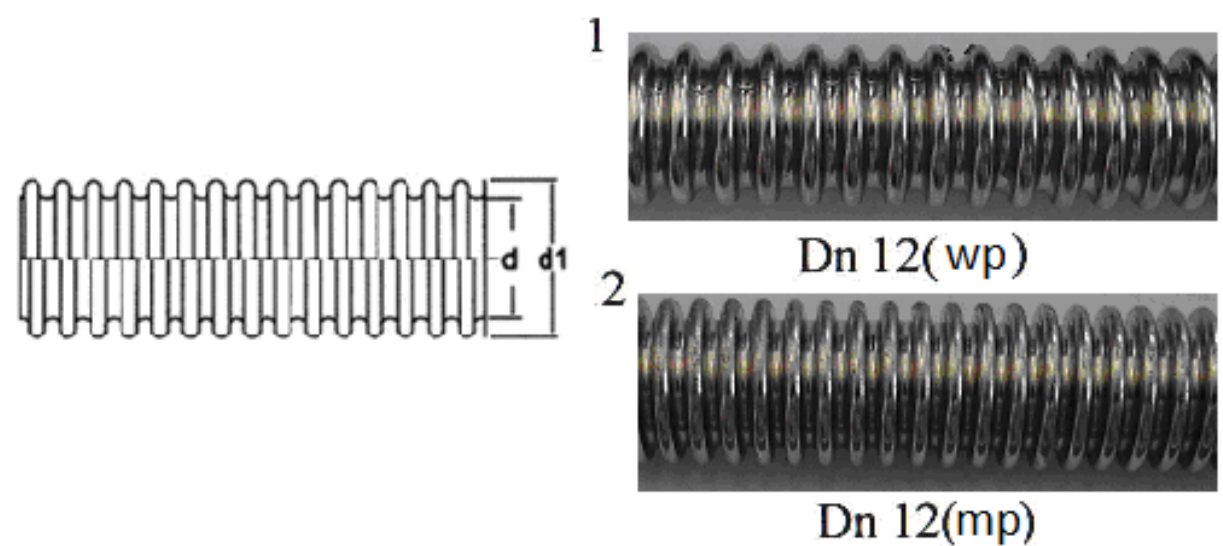

Fig. 2. Thin-walled corrugated tubes of various modifications

1 - Tube Dn12 with wide pitch distance of discrete vortex generators; 2 - tube Dn12 with medium pitch distance of discrete vortex generators

The corrugated tubes are not afraid of defrosting and water stress, compensate linear expansion and can operate at temperatures up to $150{ }^{\circ} \mathrm{C}$ and pressure of $25 \mathrm{~kg} / \mathrm{cm}^{2}$. These tubes are long service life due to the corrosion resistance and high tube strength and characterized by reliability and resistance to external and internal mechanical and hydraulic loads due to the material properties, high flexibility and elasticity.

The use of corrugated tubes of various modifications is the effective way to improve the thermal and hydraulic characteristics of heat exchangers. The corrugated tubes provide turbulence near the surface of the tube wall reducing the thickness of the thermal boundary layer. There is improved mixing of the liquid near the tube wall, due to detached disturbance from the wall to the main stream, and as a result the overall heat transfer coefficient of heat exchange systems is increased (see Fig. 3). 


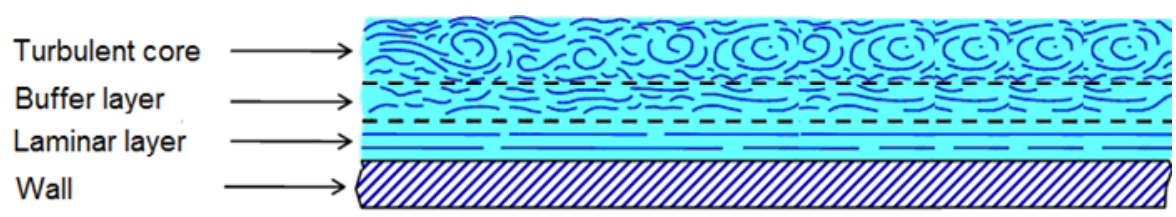

a)

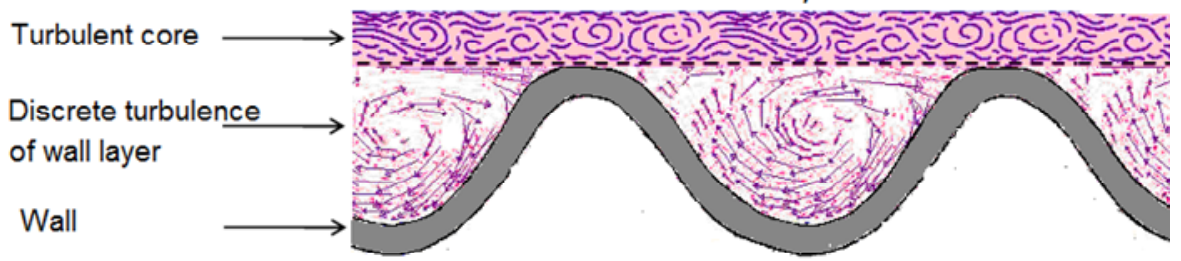

b)

Fig. 3. Scheme of flow formation in tubes of various geometries: $a$-smooth tube; $b$ - tube with discrete vortex generators.

The test laboratory stand was created to research experimental models of heat exchangers and to determine their performance. (Fig. 4) The stand was equipped with a tubular heat exchanger type "tube in tube" with a corrugated inner tube (with replacement tubes with other geometry) 2 . The water meters 5, 11 (vane) to measure the flow of hot and cold coolant were installed at the stand. Thermocouple chromel-kopel (HC) was used for determining the temperature of the coolant inlet and outlet (in the tube, between and on the walls of the tube) of the heat exchanger 14. The pressure sensors 12, 13 (DANFFOS company) for fixing the flow pressure at the inlet and outlet of the heat exchanger tubes were installed. The analog-to-digital converter (ADC) of the type I-7018 was included to stand hardware system to ensure the conversion of input signals from the thermocouples and pressure transducers to digital form and transmitting the data to the computer 15 . The sensors to measure the thermal hydraulic flow conditions were used at the stand. The comparative analysis of operation modes of the heat exchanger with a corrugated inner tube (various modifications) and the heat exchanger with a smooth inner tube was carried out according to the results of experimental studies. 


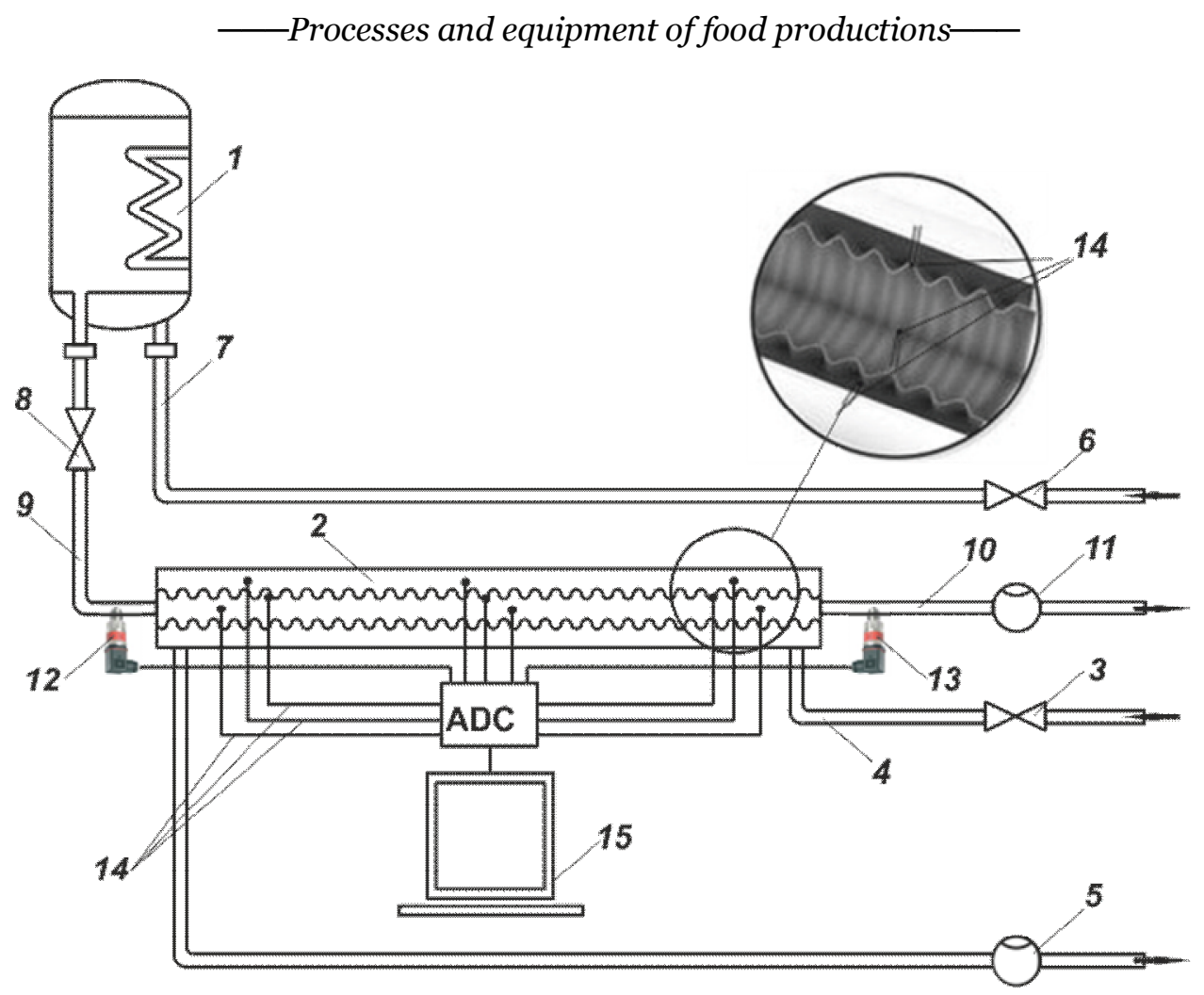

Fig. 4. Schematic diagram of the laboratory stand for the experimental study of heat transfer in corrugated tube heat exchangers based on tubes with discrete vortex generators:

1 - insulated boiler; 2 - tube in tube heat exchanger; 3 - cold coolant supply valve;

4 - cold coolant feeding; 5 - cold coolant flow meter; 6 - cold water supply valve;

7 - cold water feeding; 8 - hot coolant supply valve; 9 - hot coolant feeding;

10 - hot coolant drain; 11 - hot coolant flow meter; 12, 13 - sensors (DANFFOS company) for measuring the pressure at the inlet and outlet of the heat exchanger;

14 - thermocouples Chromel-Kopel (CK); 15 - personal computer.

\section{Results and discussion}

The results and heat transfer coefficient according to the coolant flow rate in corrugated tubes comparing with a smooth tube are demonstrated in Fig. $5-6$. The convective heat transfer coefficient of corrugated tubes comparing with a smooth tube is considerably increased under the same flow conditions. The efficiency rise of the heat transfer coefficient is in the range of 2,0 to 2.6, and goes up with increasing Reynolds number. The increase of heat transfer is more than growth of hydraulic resistance at the same time. 


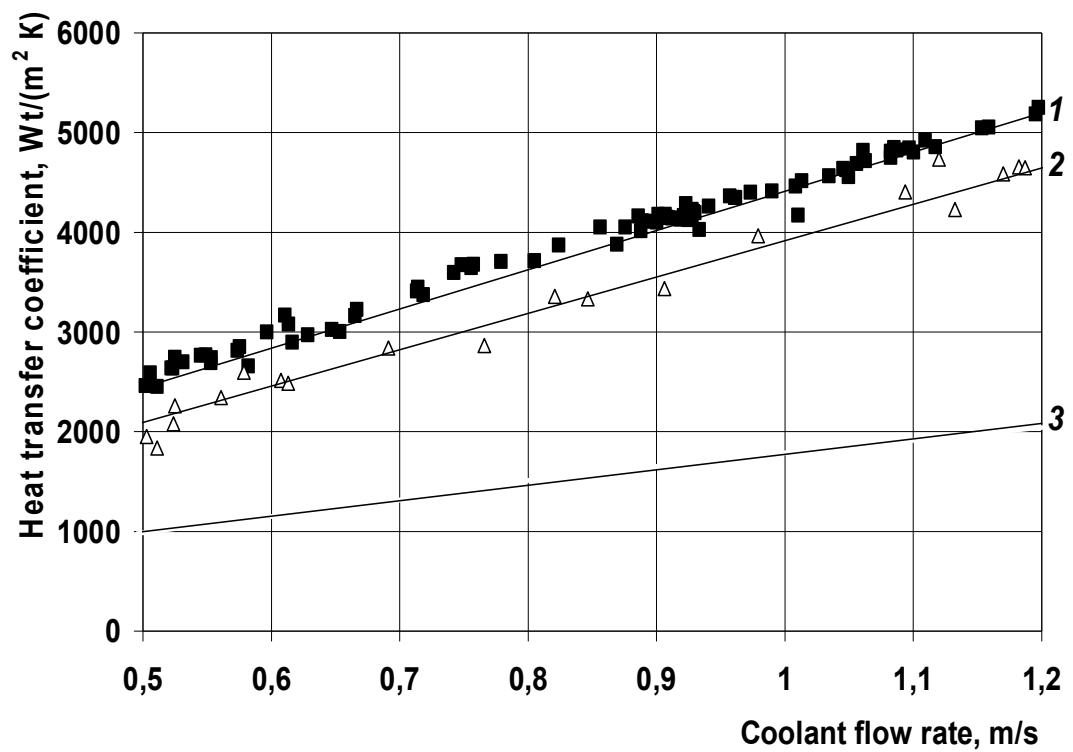

Fig. 5. Dependence of the heat transfer coefficient of the corrugated and smooth tubes on coolant flow rate:

1 - tube Dn12 with wide pitch distance of discrete vortex generators;

2 - tube Dn12 with medium pitch distance of discrete vortex generators; 3 - smooth tube.

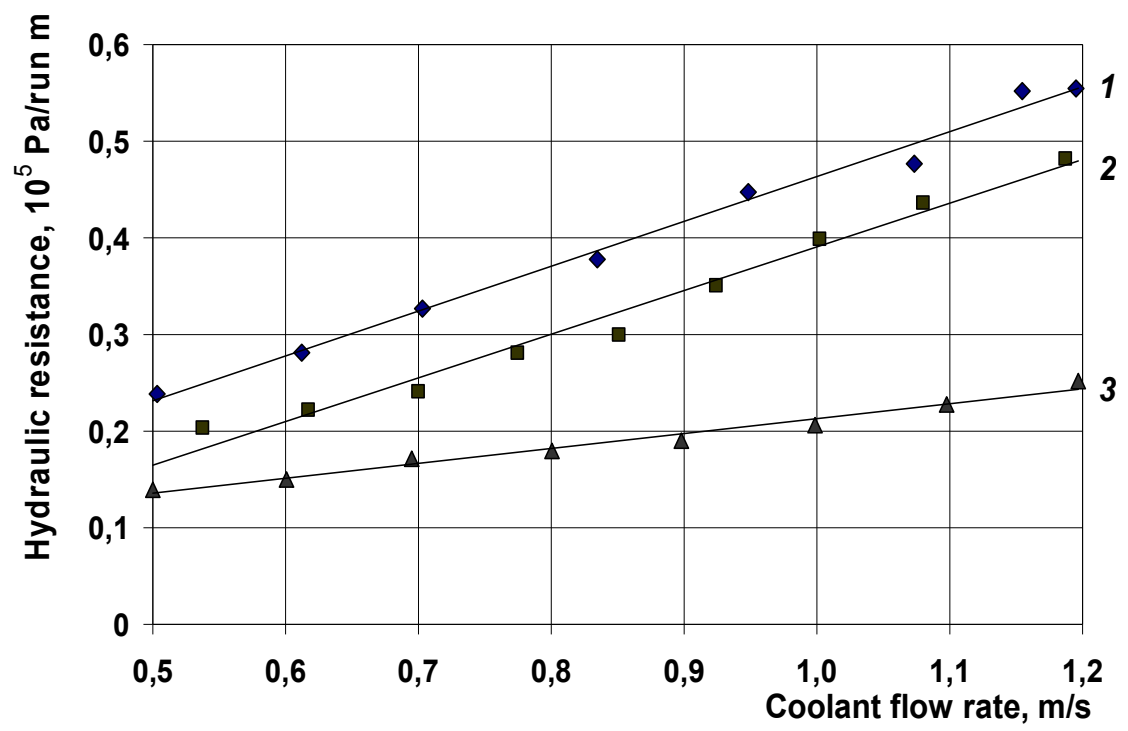

Fig. 6. Dependence of hydraulic resistance of the corrugated and smooth tubes on coolant flow rate:

1 - tube Dn12 with wide pitch distance of discrete vortex generators;

2 - tube Dn12 with medium pitch distance of discrete vortex generators;

3 - smooth tube. 
The criterial dependences of the flow inside fold and in the annular fold of the corrugated tube were obtained in integrating experimental data. As the basic the equation for the tube flow was used to generalize the experimental data for inner fold of the tubes with discrete vortex generators:

$$
\overline{N u_{d}}=C \cdot \operatorname{Re}_{d}^{m} \cdot \operatorname{Pr}_{l q}^{0,43} \cdot\left(\frac{\operatorname{Pr}_{l q}}{\operatorname{Pr}_{w}}\right)^{0,25}
$$

the value of the constant $C$ and the exponent $m$ were determined by the statistical processing of the experimental data. For this purpose the experimental data was presented in a logarithmic coordinate system:

$$
F^{*}=\lg \left(\frac{\overline{N u_{l q}}}{\operatorname{Pr}_{f}^{0.43} \cdot\left(\operatorname{Pr}_{f} / \operatorname{Pr}_{w}\right)^{0.25}}\right)=\lg C+m \lg \left(\operatorname{Re}_{d}\right)
$$

where the experimental data are located near the straight line (Fig. 7) with a constant $C=$ 0.79 and the exponent $m=0,66$ in Equation (2).

The value of the exponent $m=0.66$ generally corresponds to the transitional regime. Since the experiments were carried out at Reynolds numbers of more than 9000, it can be considered that the flow in the corrugated tube was turbulent. Additional processing of the experimental data was performed in the equation (1) with an exponent $m=0.8$ at Reynolds number.

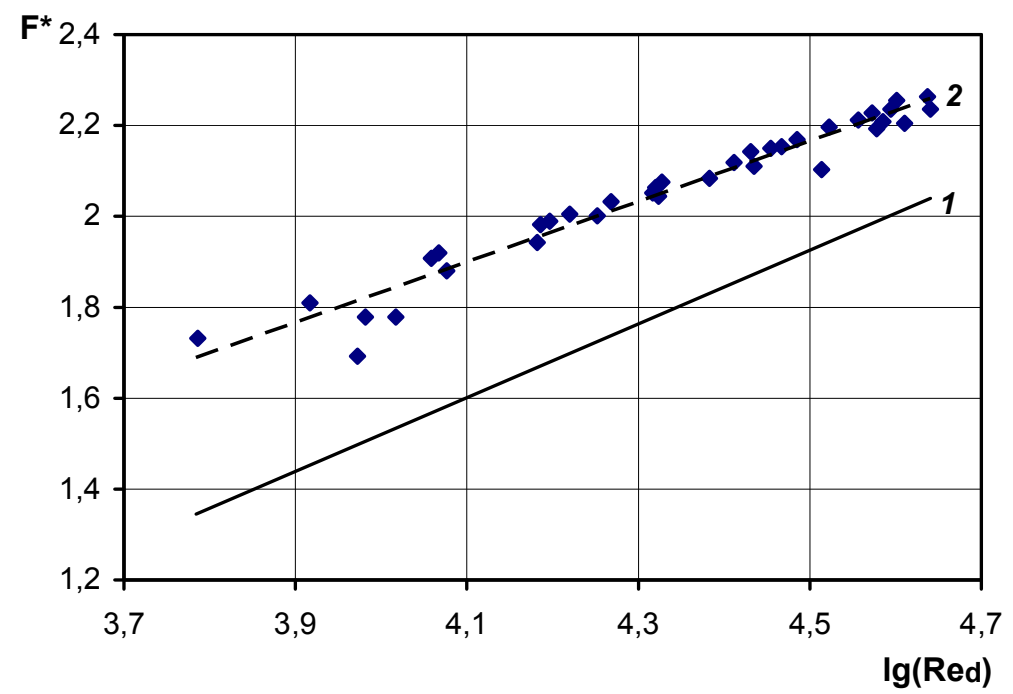

Fig. 7. Generalized results of experimental data of heat transfer inside corrugated tube:

1 - equation for the average heat exchange in tubes at the stabilized flow $\overline{N u_{d}}=0,021 \cdot \operatorname{Re}_{d}^{0,8} \cdot \operatorname{Pr}_{l q}^{0.43}$; 2 - approximation of experimental data. 
The constant $C$ is not constant, as it follows from the represented coordinate system Fig. 7, and depends on the Reynolds number and is determined by the equations:

$$
\begin{aligned}
\lg (C) & =-0.02 \cdot \lg \left(\operatorname{Re}_{d}\right)+0,12 \\
C & =10^{-0.02 \cdot \lg \left(\mathrm{Re}_{d}\right)+0.12}
\end{aligned}
$$

In this case, the equation for the average heat exchange inside fold of tube takes the following form:

$$
\overline{N u_{d}}=10^{-0.02 \cdot \lg \left(\mathrm{Re}_{d}\right)+0.12} \cdot \operatorname{Re}_{d}^{0.8} \cdot \operatorname{Pr}_{l q}^{0.43} \cdot\left(\frac{\operatorname{Pr}_{l q}}{\operatorname{Pr}_{w}}\right)^{0,25}
$$

It is used in Figure 8:

$$
F^{* *}=\lg \left(\frac{\overline{N u_{d}}}{\operatorname{Pr}_{f}^{0,43} \cdot\left(\operatorname{Pr}_{f} / \operatorname{Pr}_{w}\right)^{0,25} \cdot \operatorname{Re}_{d}^{0,8}}\right)
$$

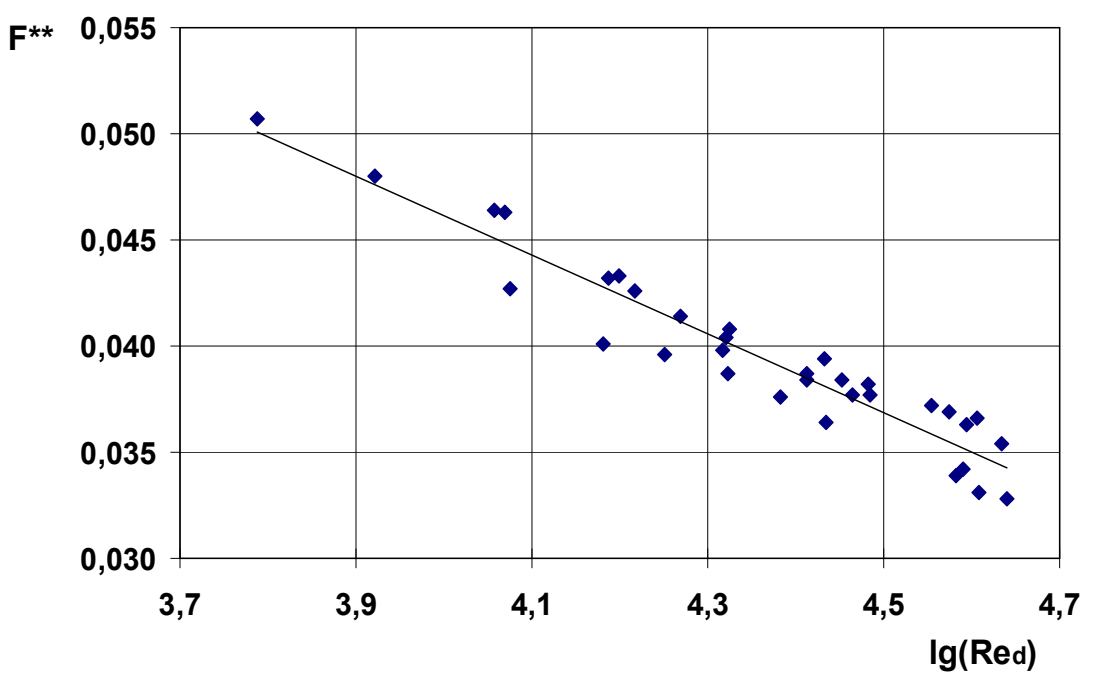

Fig. 8. Generalized results of experimental data of heat transfer inside fold of tube with exponent $m=0.8$ at Reynolds number

The analogical generalization of experimental data was performed for the average heat exchange in the annular fold. The results in semi-log plot with the definition of the constant $C$ and exponent $m$ are shown in Fig. 9. In this case, the constant $C$ is equal to 1.77, and the exponent $m=1,0$. 


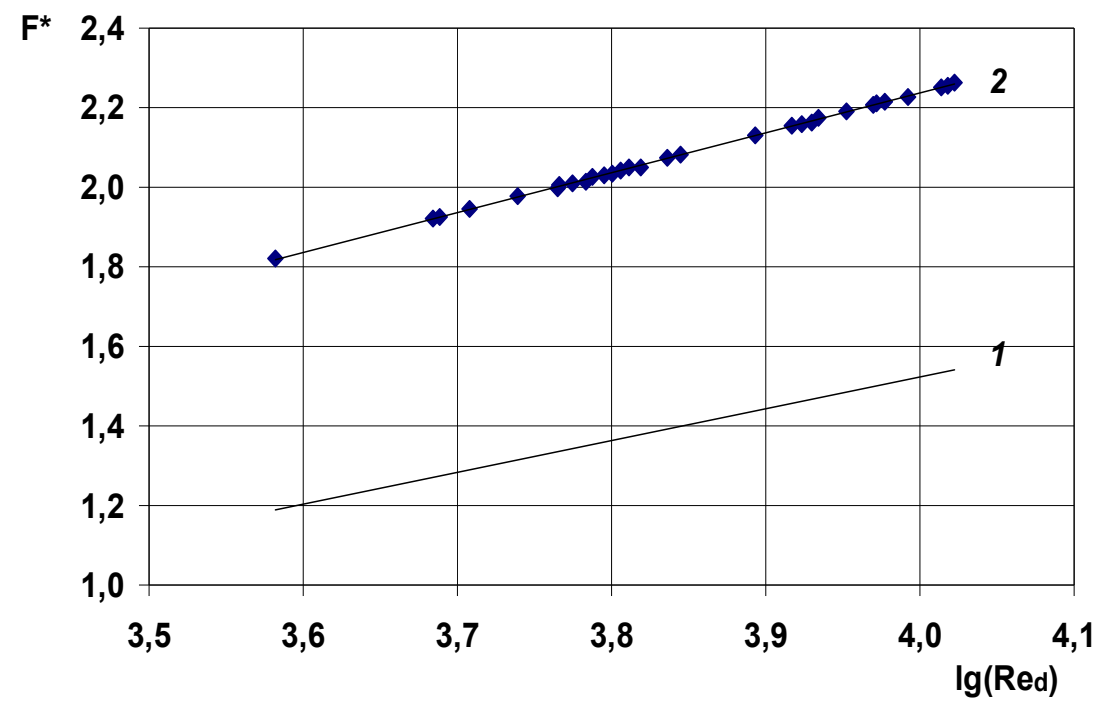

Fig. 9. Generalized results of experimental data of heat transfer inside annular fold:

1 - equation for the average heat exchange in tubes at the stabilized flow $\overline{N u_{d}}=0,021 \cdot \operatorname{Re}_{d}^{0,8} \cdot \operatorname{Pr}_{l q}^{0.43}$; 2 - generalizing straight line.

The value of the exponent $m$ does not correspond to the physical heat exchange in the annular fold because the data was obtained at Reynolds number more of 4000 . There is assumed a turbulent regime in the annular fold despite the low Reynolds number corresponding to the transition mode during axial flow. Figure 10 shows generalization of experimental data performed with the exponent $m=0.8$ at Reynolds number.

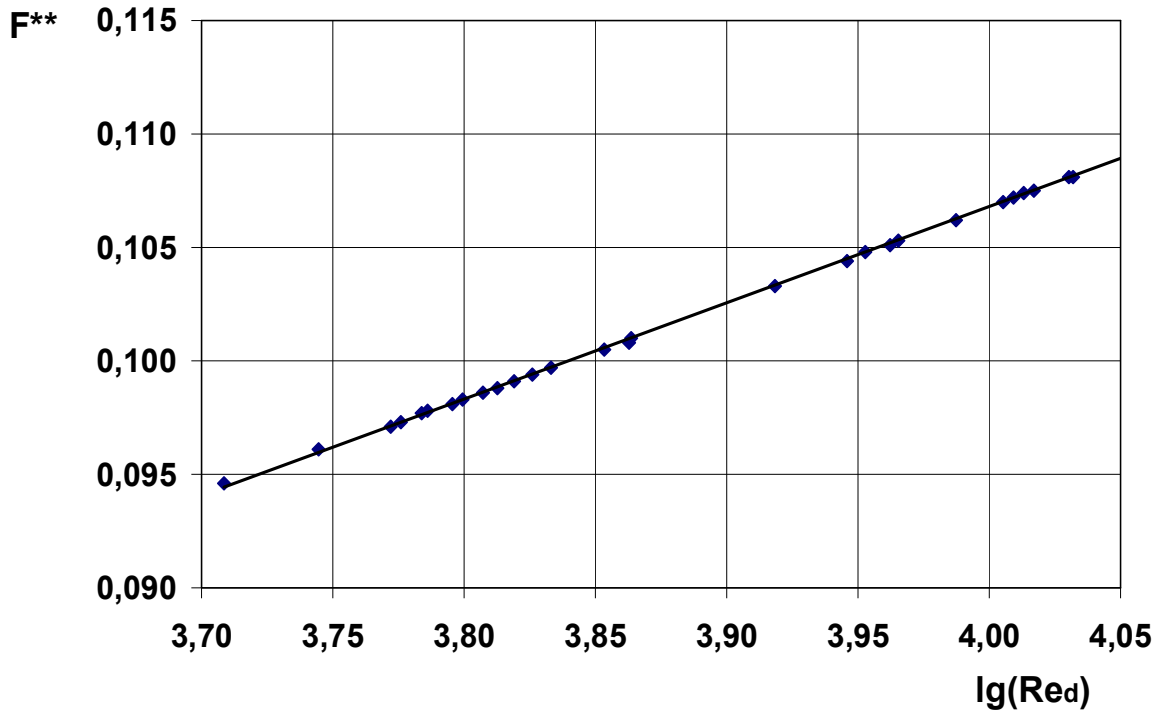

Fig. 10. Generalized results of experimental data of heat transfer inside annular fold of corrugated tube with exponent $m=0.8$ at Reynolds number 

system:

The equation for the constant $C$ is defined by the relationship in the present coordinate

$$
\begin{gathered}
\lg (C)=0.05 \cdot \lg \left(\operatorname{Re}_{d}\right)-0,08 \\
C=10^{0.05 \cdot \lg \left(\mathrm{Re}_{d}\right)-0.08}
\end{gathered}
$$

and the equation for the average heat transfer in the annular fold takes the following form:

$$
\overline{N u_{d}}=10^{0.05 \cdot \lg \left(\mathrm{Re}_{d}\right)-0,08} \cdot \operatorname{Re}_{d}^{0.8} \cdot \operatorname{Pr}_{l q}^{0.43} \cdot\left(\frac{\operatorname{Pr}_{l q}}{\operatorname{Pr}_{w}}\right)^{0,25}
$$

The results show that the mathematical calculations are quite close to the experimental research. The obtained criterial dependences allow developing a methodology for engineering calculations for the design of new effective heat exchangers.

Theoretical and experimental studies show the prospects of this direction and allow creating effective heat exchangers with thin-walled stainless steel flexible corrugated tubes. Comparative heat engineering tests of the new heat exchanger $350 \mathrm{~kW}$ were successfully carried out in the administrative building of the IET of NASU.

\section{Conclusions}

1. The heat transfer coefficient in new corrugated tube heat exchangers with discrete vortex generators tubes is $1.1-1.2$ times more the average value of $\mathrm{k}$ for plate heat exchangers.

2. The metal consumption of new corrugated tube heat exchangers with discrete vortex generator tubes is almost 1.5 times less compared to plate heat exchanger of the same capacity.

3. The unit cost of heat exchange surface of corrugated tube heat exchangers is much less compared to that of plate heat exchangers. It is a significant reserve to reduce the cost of heat exchange equipment and to create competitive heat exchange systems.

\section{References}

1. Kuppan Thulukkanam (2013), Heat Exchanger Design Handbook, Second Edition, CRC Press.

2. Dreytser G.A. (1995), Problemy sozdaniya kompaktnyh trubchatyh teploobmennyh apparatov, Teploenergetika, 3, pp. 11-18.

3. George D. Saravacos and Athanasios E. Kostaropoulos, (2002), Handbook of food processing equipment, Plenum Press Publishers, New York.

4. Konoplev A.A., Aleksanyan G G., Rytov B.L., Berlin A.l. (2015), On efficient tubular heat exchangers, Theoretical Foundations of Chemical Engineering, 49(1), pp 61-69.

5. Pan M., Jamaliniya S., Smith R., Bulatov I., Gough M., Higley T., Droegemueller P.,(2013) New insights to implement heat transfer intensification for shell and tube heat exchangers, Energy, 57(1), pp. 208-221.

6. Hasanpour A., Farhadi M., Sedighi K., (2016) Experimental heat transfer and pressure drop study on typical, perforated, V-cut and U-cut twisted tapes in a 
helically corrugated heat exchanger, International Communications in Heat and Mass Transfer, 71, pp. 126-136.

7. Seong-Yeon Yoo, Dong-Seong Park, Min-Ho Chung, Sang-Yun Lee (2002), Heat transfer enhancement for fin-tube heat exchanger using vortex generators, Journal of Mechanical Science and Technology, 16, pp 109-115.

8. Seong Won Hwang, Dong Hwan Kim, June Kee Min, Ji Hwan Jeong (2012), CFD analysis of fin tube heat exchanger with a pair of delta winglet vortex generators, Journal of Mechanical Science and Technology, 26, pp 2949-2958.

9. Hrabov L.N., Chalaev D.M., Korol Y.V. (2012), Eksperimentalnoe issledovaniie protsessa teploperedachi $\mathrm{v}$ trubchatykh teploobmennikakh $\mathrm{s}$ diskretnymi turbulizatorami, Naukovi pratsi ONAHT, 1(41), pp.187-190.

10. Dolinskyi A.A., Chalaev D.M., Hrabov L.N., Pereiaslavtseva O.O., Sylniahina N.B., Kovalov V.V. (2013), Rozrobka efektyvnykh teploobminnykiv novoho pokolinnia na osnovi trub $\mathrm{z}$ dyskretnymy turbulizatoramy, Enerhetyka ta elektryfikatsiia, 4(13), pp.28-33.

11. Hrabov L.M., Chalaev L.M., Pereiaslavtseva E.A., Sylniahyna N.B., (2014), Razrabotka konkurentnosposobnykh trubchatykh teploobmennyh apparatov, Naukovi pratsi ONAHT, 2(45), pp. 93-97.

12. Available at: http://www.eco-flex.com.ua 